\title{
A pilot study of the effect of masticatory muscle training on facial growth in long-face children
}

\author{
Bengt Ingervall and Elias Bitsanis \\ Orthodontic Clinic, University of Bern, Switzerland
}

\begin{abstract}
SUMMARY Daily chewing of a tough chewing material consisting of resin from a pine tree (Mastix from the island of Chios, Greece) was instituted in 13 children (aged 7-12 years) with long-face morphology. The chewing exercise therapy was maintained for one year and aimed at revealing the possibility of strengthening the masticatory muscles and influencing facial growth.

Masticatory muscle strength was monitored by measurement of bite force and electromyographic recording of the activity of the anterior temporal and masseter muscles during biting and chewing. The facial morphology was recorded with profile cephalograms and dental casts.

During the one-year experimental period, there was a significant increase in bite force and muscle activity during maximal bite. The change was already evident at the first control recording 3 months after the start of the chewing exercise therapy. The muscle activity during chewing of apple and peanuts did not change significantly.

The facial growth was characterized by anterior mandibular rotation in 9 of 12 cases while a posterior rotation occurred in 2 cases. The anterior rotation was, on average, 2.5 degrees and thus considerably greater than would be expected during normal growth. There were no signs of reduced vertical growth of the maxilla, a reduced rate of molar eruption or increased growth of the mandible.
\end{abstract}

\section{Introduction}

It is well-known that individuals with a so-called long-face morphology have weak facial muscles. The long-face morphology (dolichofacial type) is characterized by a large anterior face height (particularly lower face height), a small posterior face height, a steep mandibular plane and a large gonial angle. This type of facial morphology predisposes to skeletal open bite. In the short-face (brachyfacial type) with the opposite facial characteristics (small anterior face height, flat mandibular plane, small gonial angle) the masticatory muscles are strong.

The variation of masticatory muscle strength with facial type is known from measurements of bite force in adults by, among other workers, Ringqvist (1973), Helkimo and Ingervall (1978) and, recently, Proffit et al. (1983). A tendency to low bite force values in children with the longface morphology was found by Proffit and Fields (1983). A corresponding variation of the activity of the masticatory musculature with facial type was demonstrated electromyographically in adults by Möller (1966) and in children by Ahlgren (1966), Ingervall and Thilander (1974) and Ingervall (1976).

It is not known whether the facial morphology determines the strength of the masticatory muscles or whether a strong musculature influences the form of the face. Studies of young adults with small and large bite forces revealed a smaller variation in the facial morphology in the individuals with large bite force (Ingervall and Helkimo, 1978). This argues for the primary importance of the masticatory muscles in forming the face. Strong muscles form the face to a specific type while the facial form in individuals with weak muscles varies more because the muscles exert less influence.

If the facial form is partly determined by the strength of the masticatory muscles, this could open up therapeutic possibilities. Exercises aiming at strengthening the muscles of mastication could have a beneficial influence on a growing face of the long-face type. Such an attempt was reported by Spyropoulos (1985), who demonstrated a decrease of ftontal open bite in children 
after a prolonged period of chewing of a special tough chewing material in order to strengthen the masticatory muscles. The present study was inspired by the results of Spyropoulos and aims at further elucidating the possibilities of influencing the form of the face in children with a tendency to a long-face, by exercise with tough chewing material. At the same time, the influence of the chewing exercises on the musculature was studied by measurement of bite force and electromyographic muscle activity.

\section{Subjects and methods}

Thirteen children ( 8 boys and 5 girls) were included in the study. Their ages at the start of the investigation varied between 7 years, 6 months and 12 years, 7 months (median age 9 years, 4 months). They were selected on the grounds of a facial morphology of the 'high-angle' type, i.e. the inclination of the mandible was large (a large angle NSL/ML). The anterior face height was large and the gonial angle (angle RL/ML) was also large. They had a tendency to skeletal frontal open bite and were in a period of active growth.

\section{Morphological recordings}

The facial morphology of the sample as seen in profile cephalometric radiographs is given in Table 1. The reference points and lines used in

Table 1 Mean and range of profile cephalometric variables of the subjects studied and mean and standard deviation of the same variables in 150 unselected 9-year-old children (reference sample).

\begin{tabular}{|c|c|c|c|c|}
\hline \multirow[t]{2}{*}{ Variable } & \multicolumn{2}{|c|}{ Present subjects } & \multirow{2}{*}{$\begin{array}{l}\text { Reference } \\
\text { sample } \\
\text { Mean }\end{array}$} & \multirow{2}{*}{ s.d } \\
\hline & Mean & Range & & \\
\hline$n-s-a r^{0}$ & 126.2 & $114-138$ & 124.2 & 4.9 \\
\hline $3-n-5 s^{0}$ & 80.3 & $76-86$ & 81.0 & 3.4 \\
\hline$s-n-s m^{0}$ & 74.8 & $70-80$ & 76.6 & 3.2 \\
\hline $\mathbf{s s - n - s m ^ { 0 }}$ & 5.5 & $0-9$ & 4.4 & 2.2 \\
\hline NSL/NL ${ }^{\circ}$ & 6.7 & $0-11$ & 6.8 & 3.2 \\
\hline NSL/OL ${ }^{\circ}$ & 21.5 & $17-27$ & 18.7 & 3.8 \\
\hline NSL/ML & 42.4 & $34-50$ & 33.7 & 4.7 \\
\hline NLAML ${ }^{\circ}$ & 35.8 & $32-44$ & 26.9 & 4.4 \\
\hline s-tgo/n-me $\times 100$ & 59.0 & $54-64$ & 65.5 & 4.4 \\
\hline$n-s p^{\prime} / s p^{\prime}-m e \times 100$ & 73.8 & $65-86$ & 81.4 & 5.9 \\
\hline RL/ML ${ }^{\circ}$ & 131.8 & $125-142$ & 124.9 & 5.4 \\
\hline$n-s-g n^{0}$ & 72.8 & $66-79$ & 67.5 & 3.5 \\
\hline is-io (mm) & 4.6 & $0-10$ & 4.8 & 2.1 \\
\hline ii-io (mm) & -0.5 & $-5-3$ & 2.7 & 1.9 \\
\hline
\end{tabular}

the cephalometric analysis are given in Figures 1 and 2 . The profile radiographs were taken with the mandible in the intercuspal position. Table 1 also gives the mean and standard deviation of the variables measured in an unselected reference sample of 9-year-old children ( 73 boys and 77 girls) with the same ethnic background as the present subjects (Feller, 1986).

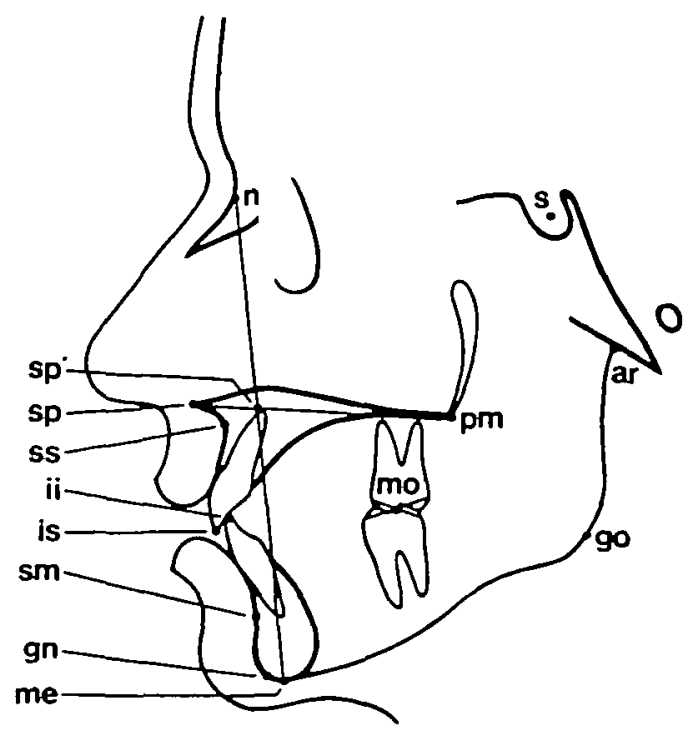

Figure 1 Reference points used in the cephalometric analysis.

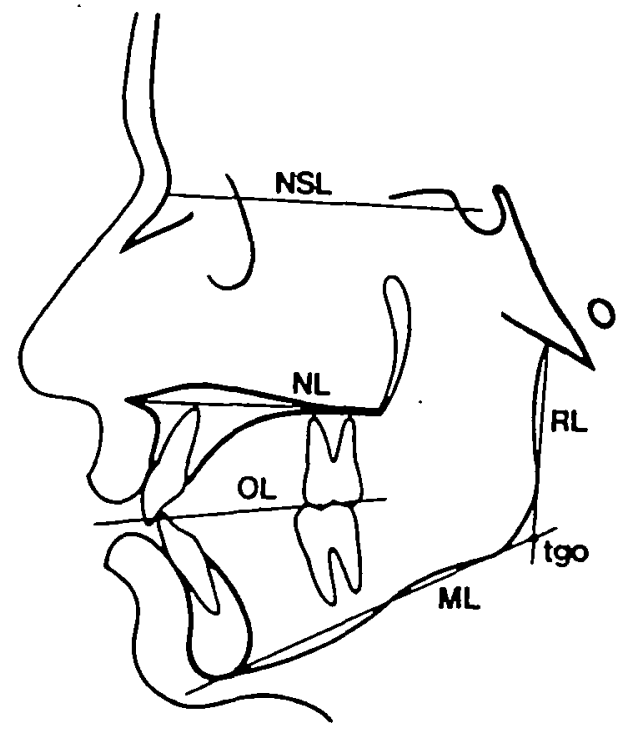

Figure 2 Reference lines used in the cephalometric analysis. 
The reference line OL was defined as a line from mo bissecting the distance is-ii (Feller, 1986). The point io was constructed as the perpendicular projection of the point ii on to the line mo-is (upper occlusal line). The distances is-io and ii-io give the overjet and overbite respectively and were in cases of double projections measured from the central incisor in the most extreme position. The quotients s-tgo/n-me $\times 100$ and n-sp'/ $\mathrm{sp}^{\prime}$-me $\times 100$ express the relation between the posterior and anterior face heights and the upper and lower anterior face heights, respectively.

The widths of the upper and lower dental arches between the first permanent molars were measured on dental casts with sliding calipers to $1 / 10 \mathrm{~mm}$. The measuring points were those described earlier (Thüer et al., 1985).

The total rotation of the mandible from the start to the end of the period of observation was analysed by superimposition of profile cephalographs using natural reference structures of the mandible as described by Björk and Skieller (1983).

\section{Measurement of bite force}

The bite force in the region of the right and the left first permanent molars was measured with a bite force recorder as described by Flöystrand et al. (1982). Thin acrylic splints covering the occlusal surfaces of the teeth in the two dental arches were used in order to allow biting on the sensor loading it at right angles (Fig. 3). Three measurements on each side of the dental arch were made in random order. The highest of the three recorded values was used as the maximum bite force at that location.

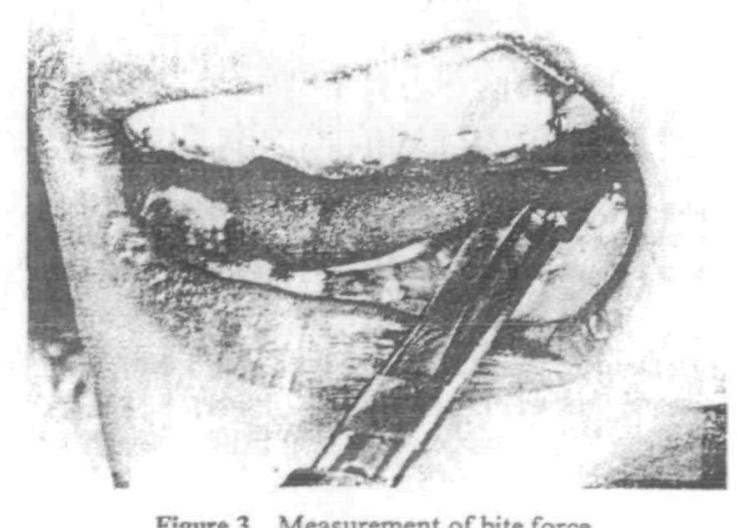

Figure 3 Measurement of bite force.

\section{Electromyographic recording}

The activity of the anterior portion of the temporal muscle and of the masseter muscle was recorded bilaterally with bipolar hook electrodes (Ahlgren, 1967). The placement of the electrodes was as described earlier (Ingervall and Thilander, 1974; Ingervall and Egermark-Eriksson, 1979).

Recordings were made with a Disa electromyograph and a Gould electrostatic writer (for details see Ingervall and Bitsanis, 1986) in the rest position of the mandible, during maximal bite in the intercuspal position and during chewing of apple and peanuts. For the recordings, the child was placed in a dental chair, in an upright position, without a head-rest. For the chewing test, the child was given a standard sized piece of apple or 3 peanuts and asked to chew in the habitual way. The order of the recordings was as follows: in the rest position of the mandible; during chewing of apple, and of peanuts; during maximal bite in the intercuspal position, and a new recording in the rest position of the mandible.

The mean voltage amplitude in the rest position was measured when the muscle activity was minimal during at least five secorids (mean of recordings 1 and 5). The mean voltage amplitude of the characteristic activity during maximal bite was measured. The maximal mean voltage amplitude during the closing phase of the chewing cycle was determined as the mean of six randomly selected cycles during an act of chewing.

\section{Muscle training with chewing gum}

The training was started after initial morphological recordings with $x$-ray cephalometry and dental casts, and electromyographic and bite force recordings. A special type of chewing-gum was used. The material, available under the name of Mastix, is a natural product (resin from a pine tree growing on the Greek island of Chios). The product is well known and popular as a chewing material in Greece. It is much tougher to chew than ordinary chewing-gum and retains its tough consistency during long periods of chewing. The children were requested to chew the resin for at least two hours per day and to make daily records of the duration of the chewing.

\section{Experimental period and control recordings}

The children were followed up for one year. During this time, they chewed the resin as described abnve. Appointments were arranged 
Table 2 Mean bite force (in $N$ ) and mean voltage amplitude (in $\mu \mathrm{V}$ ) in the rest position of the mandible and during maximal bite and chewing at recordings 1-4. Mean of right and left sides.

\begin{tabular}{|c|c|c|c|c|c|}
\hline & \multicolumn{4}{|c|}{ Recording } & \multirow[t]{2}{*}{ Significant difference } \\
\hline & 1 & 2 & 3 & 4 & \\
\hline Bite force & 334 & 372 & 395 & 436 & $1-2^{x}, 1-3 x, 1-4 x, 2-4 x, 3-4 x$ \\
\hline $\begin{array}{l}\text { Amplitude in rest position } \\
\text { Anterior temporal muscle } \\
\text { Masseter muscle }\end{array}$ & $\begin{array}{l}2.3 \\
1.4\end{array}$ & $\begin{array}{l}2.4 \\
1.4\end{array}$ & $\begin{array}{l}2.9 \\
0.9\end{array}$ & $\begin{array}{l}1.4 \\
1.3\end{array}$ & $\begin{array}{l}\text { N.S. } \\
\text { N.S. }\end{array}$ \\
\hline $\begin{array}{l}\text { Amplitude during maximal bite } \\
\text { Anterior temporal muscle } \\
\text { Masseter muscle }\end{array}$ & $\begin{array}{l}336 \\
170\end{array}$ & $\begin{array}{l}483 \\
258\end{array}$ & $\begin{array}{l}507 \\
299\end{array}$ & $\begin{array}{l}513 \\
283\end{array}$ & $\begin{array}{l}1-2 x x, 1-3 x x, 1-4 x x \\
1-2 x, 1-3 x, 1-4 x x\end{array}$ \\
\hline $\begin{array}{l}\text { Amplitude during chewing of apple } \\
\text { Anterior temporal muscle } \\
\text { Masseter muscle }\end{array}$ & $\begin{array}{l}295 \\
151\end{array}$ & $\begin{array}{l}315 \\
164\end{array}$ & $\begin{array}{l}336 \\
180\end{array}$ & $\begin{array}{l}320 \\
175\end{array}$ & $\begin{array}{l}\text { N.S. } \\
\text { N.S. }\end{array}$ \\
\hline $\begin{array}{l}\text { Amplitude during chewing of peanuts } \\
\text { Anterior temporal muscle } \\
\text { Masseter muscle }\end{array}$ & $\begin{array}{l}331 \\
169\end{array}$ & $\begin{array}{l}364 \\
193\end{array}$ & $\begin{array}{l}413 \\
231\end{array}$ & $\begin{array}{l}390 \\
208\end{array}$ & N.S. \\
\hline
\end{tabular}

$$
x=0.01<P<0.05, x x=0.001<P<0.01
$$

every fourth week for the measurement of bite force. Electromyographic recordings were made at the start and after 3, 6 and 12 months of chewing-gum therapy. After 12 months, new cephalometric recordings and new dental casts were made.

\section{Results}

\section{Bite force and muscle activity}

The bite force at the start of the experiment (recording 1) and after 3 (recording 2), 6 (recording 3) and 12 (recording 4) months of muscle training is given in Table 2 and Figure 4. The Table also shows the electromyographically recorded muscle activity in the rest position and during biting and chewing. The values for bite force and muscle activity were calculated as the mean of the right and left sides.

On average, there was a gradual increase in bite force during the one year experimental period and a statistically significant increase was found on comparison between each of the recordings, except between recordings 2 and 3. Wilcoxon's matched pair signed ranks test was used for all statistical analyses. The muscle activity in the rest position of the mandible was unchanged during the period of observation.

The amplitude during maximal bite in the intercuspal position was significantly greater at recording 2 and at the following two recordings

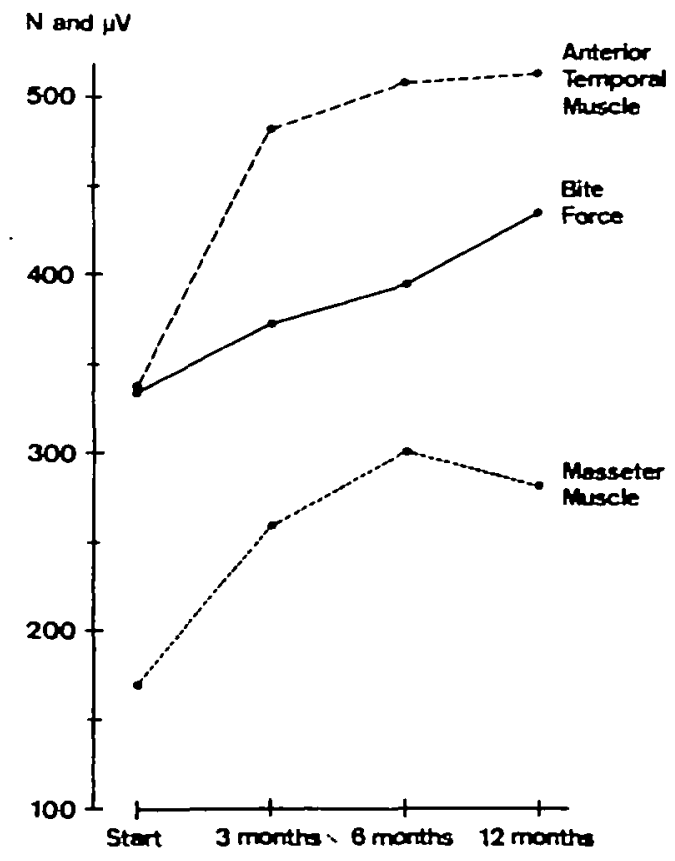

Figure 4 Average bite force (in Newtons) and amplitude of the anterior temporal and masseter muscles during maximal bite (in $\mu \mathrm{V}$ ) on four occasions during the experimental period.

than at recording 1 . There was also a numerical increase between recordings 2 and 3. During chewing, the maximal amplitude increased numerically from recording 1 to recording 2 and to recording 3 . This increase was statistically 
Table 3 Maximal mean voltage amplitude during chewing in per cent of the mean voltage amplitude during maximal bite.

\begin{tabular}{|c|c|c|c|c|}
\hline & \multicolumn{4}{|c|}{ Recording } \\
\hline & 1 & 2 & 3 & 4 \\
\hline $\begin{array}{l}\text { Amplitude during chewing of apple } \\
\text { Anterior temporal muscle } \\
\text { Masseter muscle }\end{array}$ & $\begin{array}{l}88 \\
89\end{array}$ & $\begin{array}{l}65 \\
64\end{array}$ & $\begin{array}{l}66 \\
60\end{array}$ & $\begin{array}{l}62 \\
62\end{array}$ \\
\hline $\begin{array}{l}\text { Amplitude during chewing of peanuts } \\
\text { Anterior temporal muscie } \\
\text { Masseter muscie }\end{array}$ & $\begin{array}{l}99 \\
99\end{array}$ & $\begin{array}{l}75 \\
75\end{array}$ & $\begin{array}{l}81 \\
77\end{array}$ & $\begin{array}{l}76 \\
74\end{array}$ \\
\hline
\end{tabular}

significant only for the masseter muscle when chewing peanuts (Table 2). The amplitude during chewing in per cent of the amplitude during maximal bite is given in Table 3 .

Due to the marked rise in amplitude between recordings 1 and 2 during maximal bite and the less marked change in amplitude during chewing, the proportions between the amplitude used during chewing and during maximal bite changed drastically (Table 3). After 3 months of chewinggum therapy, a considerably smaller proportion of the maximal muscle activity was used during chewing than before the period of muscle training. After the change brought about during the first 3 months of muscle training, the relations remained unchanged during the rest of the period of observation.

\section{Changes in facial and bite morphology}

The changes in facial morphology from the start of the period of muscle training to the recordings after 12 months are shown in Table 4.

During the one-year period of observation, there was a significant increase in mandibular prognathism (angle $s-n-s m$ ) and a change in sagittal jaw relation (angle ss-n-sm), and a significant decrease in inclination of the occlusal line (angle NSL/OL) and of the mandible (angle NSL/ML). The vertical jaw relation (angle NL/ ML) decreased significantly. There was a significant change in the relation between the posterior and the anterior face heights (index $\mathrm{s}$-tgo/n-me). On average, the posterior face height increased $2.5 \mathrm{~mm}$ and the anterior face height $2.0 \mathrm{~mm}$. There was a significant increase in overbite (distance ii-io). The widths of the dental

Table 4 Changes in cephalometric variables (mean and range) between recordings 1 and 4 . A minus sign denotes a smaller value at recording 4 .

\begin{tabular}{|c|c|c|c|c|}
\hline \multirow[t]{2}{*}{ Variable } & \multicolumn{3}{|c|}{ Difference between recordings 1 and 4} & \multirow{2}{*}{$\begin{array}{l}\text { Riolo et } \\
\text { al. (1974) }\end{array}$} \\
\hline & Mean & Range & Significance & \\
\hline n-s-ar ${ }^{0}$ & 0.0 & $+1.8--2.4$ & N.S. & \\
\hline s-n-ss ${ }^{0}$ & -0.2 & $+2.0--1.6$ & N.S. & +0.1 \\
\hline$s-n-s m^{0}$ & +0.8 & $+2.9--1.2$ & $0.01<P<0.05$ & -0.1 \\
\hline ss-n-smo & -1.0 & $+0.6-2.3$ & $P<0.01$ & +0.2 \\
\hline NSL/NL ${ }^{0}$ & 0.0 & $+1.1--0.8$ & N.S. & -0.2 \\
\hline NSL/OL ${ }^{\circ}$ & -1.3 & $+0.7--3.8$ & $P<0.01$ & +0.4 \\
\hline NSL/ML ${ }^{\circ}$ & -1.3 & $0.0--3.5$ & $\mathrm{P}<0.01$ & +0.2 \\
\hline $\mathrm{NL} / \mathrm{ML}^{0}$ & -1.2 & $+0.5--2.5$ & $P<0.01$ & +0.3 \\
\hline s-tgo/n-me $\times 100$ & +0.9 & $+3.0-1.0$ & $0.01<\mathrm{P}<0.05$ & \\
\hline $\mathrm{n}-\mathrm{sp} \mathrm{p}^{\prime} / \mathrm{sp}^{\prime}-\mathrm{me} \times 100$ & +0.2 & $+3.6-6.4$ & N.S. & \\
\hline $\mathrm{RL} / \mathrm{ML}^{\circ}$ & -0.9 & $+2.5--2.5$ & N.S. & +0.7 \\
\hline$n-s-g n^{0}$ & -0.7 & $+0.5--2.1$ & N.S. & -0.1 \\
\hline is-io (mm) & -0.4 & $+4.0--4.0$ & N.S. & \\
\hline ii-io (mm) & +1.0 & $+3.0--2.0$ & $0.01<P<0.05$ & \\
\hline n-me (mm) & +2.0 & $+4.5-+0.5$ & $P<0.01$ & $+2.3 \dagger$ \\
\hline $\mathrm{s}-\mathrm{go}(\mathrm{mm})$ & +2.4 & $+4.5-+1.5$ & $P<0.01$ & $+1.7 \dagger$ \\
\hline
\end{tabular}

$\dagger=$ reduced to the same degree of magnification as in the present study 
arches were practieally unchanged (average increase in both arches $0.3 \mathrm{~mm}$ ).

Table 4 also gives the annual changes during normal growth in the untreated longitudinal sample of Riolo et al. (1974). For comparison with the present material, the values from Riolo et al. were matched with those of the present subjects with respect to sex and age.

Superimposition of the profile radiograms from recordings 1 and 4 showed an average total anterior rotation of the mandible of 2 degrees $(P<0.01)$. It was technically possible to evaluate the degree of rotation in 12 of the 13 subjects. The mandible rotated posteriorly in two subjects (1.0 and 1.5 degrees, respectively), did not rotate in one subject, and rotated anteriorly in nine subjects (1.0 to 3.5 degrees). The amount of anterior rotation was 3.0 degrees in two subjects and 3.5 degrees in three subjects. Superimposed tracings of four children with great anterior rotation are shown in Fig. 5.

\section{Discussion}

The mean bite force of the present group of children at the start of the study was somewhat smaller than that in an unselected group of the same age examined with the same methods (Dinç and Kober, 1985) but rose during the experimental period to a value comparable to that found in 11-year-old children by the above authors. The gradual increase in bite force of the present subjects is probably an effect of the muscle training but may also partly be ascribed to a normal increase with age (average bite force in 9-year-old children $357 \mathrm{~N}$ and in 11-year-old children $424 \mathrm{~N}$, Dinç and Kober, 1985). The average rise in bite force in the present children during one year was, however, greater than that normally observed during two years.

The same electromyographic method as in the present investigation has been used in a study of children with Angle Class II, division 1 malocclusion (Ingervall and Bitsanis, 1986). In that study (median age of the children 10 years, 10 months) the mean amplitude of the anterior temporal muscle during maximal bite was $416 \mu \mathrm{V}$ and that of the masseter muscle $229 \mu \mathrm{V}$. The present children had 20-25 per cent lower amplitude during maximal bite at the start (recording 1) than the children with distal occlusion but at the end of the period of muscle training they had 23 per cent higher amplitude than the other children. After only 3 months of muscle training the amplitude was 13-16 per cent higher than that of the children with distal occlusion. During isometric muscle contraction (as during maximal bite) there is a linear relation between muscle force and the electromyographic amplitude (Ralston, 1961; Ahlgren and Oewall, 1970; Ahlgren et al., 1985). The increase in amplitude during maximal bite thus reflects an increase in muscle strength and is obviously an effect of the muscle training.

All observations of the changes in the cephalometric variables point in the same direction, i.e. a decrease in the inclination of the occlusal and mandibular planes through anterior rotation of the mandible. This development is accompanied by an increase in mandibular prognathism and overbite.

The children studied during the year tended to normalize with respect to facial morphology on comparison with the 9-year-old reference group described in Table 1. The facial morphology of the reference group conforms very closely to that of the sample of Riolo et al. (1974) which was studied longitudinally. The children studied in our region have on average the same facial morphology as the sample studied by Riolo et al. and that of a Scandinavian series (Feller, 1986). The one-year changes of the present experimental group were therefore compared with the annual changes in the sample of Riolo et al. It is obvious from Table 4 that the significant annual changes of the present subjects were much greater and opposite to those of the children studied by Riolo et al. The therapeutic muscle exercises carried out by our subjects have thus probably had an effect on the facial morphology.

The impression of a therapeutic effect of the muscle training is further substantiated by the analysis of the total mandibular rotation by the method of Björk. The average anterior mandibular rotation in the 12 children analysed was 2 degrees, with an anterior rotation of 3.0-3.5 degrees in five cases. In eight anteriorly rotating untreated boys followed longitudinally by Björk and Skieller (1983), the rotation per year at an age comparable to that of the present children was around 1 degree. The anterior rotation in most of our children is thus considerably greater than would be expected from the findings in untreated children.

The superimposition on natural mandibular reference structures revealed that the anterior 

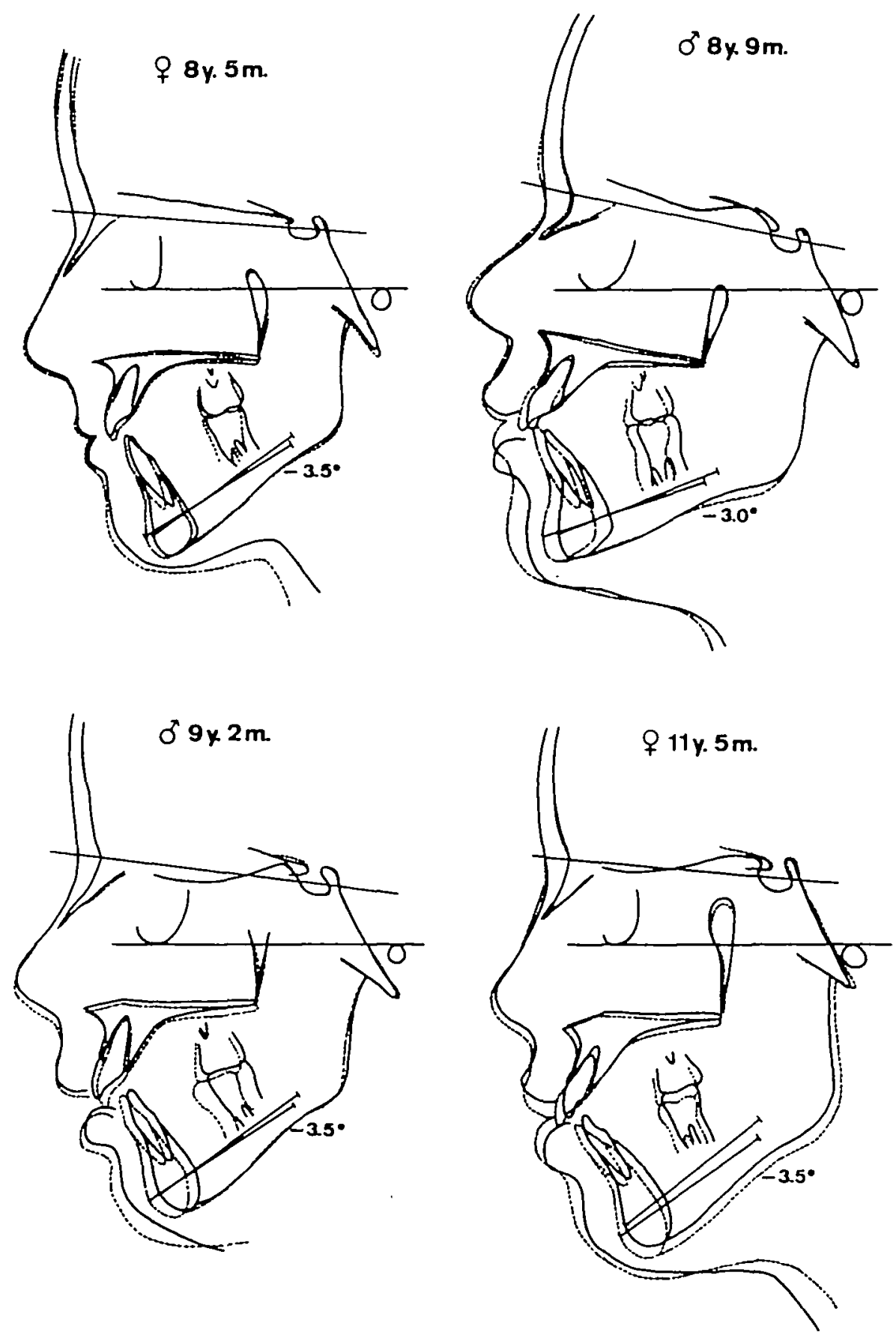

Figure 5 Superimposed profile tracings of four children with marked anterior growth rotation of the mandible during the year of muscie training. 
mandibular rotation was accompanied by resorption at the gonial angle in six cases. The resorption at the mandibular border in the gonial region varied between 0.5 and $2.5 \mathrm{~mm}$ (mean $1.3 \mathrm{~mm}$ ). This resorption explains why the angle NSL/ML decreased less than the anterior rotation (average anterior rotation in nine cases 2.5 degrees, with an average decrease of the angle NSL/ML of 1.6 degrees).

The considerable anterior mandibular rotation found in many of the present children might possibly be explained by reduced midfacial vertical growth due to increased masticatory muscle strength. If the vertical growth of the mandibular condyles exceeds that of the midface and of the alveolar processes, the mandible will rotate anteriorly, as pointed out by, for example Isaacson et al. (1981). In none of the present children was the vertical growth of the maxilla halted, however. The distance between the cephalometric reference point pm and the NSL increased between 0.5 and $1.5 \mathrm{~mm}$ (average $1.1 \mathrm{~mm}$ ). The distance between pm and the ethmoid registration point in the cranial base (used by Riolo et al.) increased on average by $1.2 \mathrm{~mm}$. This is very close to the annual increase found by Riolo $e t a l$. (1974). Björk and Skieller (1976) also found an average lowering of the palate of $1 \mathrm{~mm}$ per year during the growth period.

The lowering of the upper first molar from the nasal line was on average $1.1 \mathrm{~mm}$ in the present children. This conforms to annual changes found by Riolo et al. (1974) and Björk and Skieller (1976).

The increased muscle strength thus seems not to bring about a reduction of the vertical growth of the maxilla or to retard the eruption of the maxillary teeth. The eruption of the lower first molar measured in relation to the mandibular line $(\mathrm{ML})$ was identical (mean value $0.6 \mathrm{~mm}$ ) with that found by Riolo et al. (1974). The lower molar eruption was, however, larger (mean value $1 \mathrm{~mm}$ ) when measured in relation to the reference line based on the natural reference structures. The difference is due to the instability of the mandibular line because of the resorption in the gonial area.

There is evidence, as emphasized, of an increased anterior mandibular rotation during the year of muscle training. There is no evidence of a decreased maxillary vertical growth or a decreased molar eruption during the period of muscle training. The anterior mandibular rotation may, however, be brought about by an increased mandibular growth which could be the result of the functional stimulation due to the increased muscle strength. The growth of the mandibular condyles was estimated by measuring the distance ar-gn. This distance increased on average by $2.5 \mathrm{~mm}$ during the year of training, which is identical with the annual increase in the sample of Riolo $e t$ al. The great anterior mandibular rotation can thus not be explained by increased mandibular growth either.

The facial morphology of the present children was compared with that of children with normal occlusion or children randomly selected with respect to facial morphology. The objection might be made that the long-face children follow another pattern during their facial growth. Recent longitudinal studies of the growth of children with different facial types have, however, failed to reveal any such differences. The growth pattern was parallel and the annual increments the same in long-face children as in children with average facial morphology (Bishara and Jakobsen, 1985).

\section{Acknowledgement}

This study was supported by Schweizerischer Nationalfonds zur Förderung der wissenschaftlichen Forschung (Grant Nr. 3.832-0.83) and by the Research Fund of the Swiss Dental Association (Project Nr. 132).

\section{Address for correspondence}

Professor B. Ingervall

Klinik für Kieferorthopãdie

Freiburgstrasse 7

CH-3010 Bern

Switzerland

\section{References}

Ahlgren J 1966 Mechanism of mastication. Acta Odontologica Scandinavica 24: suppl 44

Ahlgren J 1967 An intercutaneous needle electrode for kinesiologic EMG studies. Acta Odontologica Scandinavica 25: 15-19

Ahlgren J, Oewall B 1970 Muscular activity and chewing force: A polygraphic study of human mandibular movements. Archives of Oral Biology 15: 271-280

Ahlgren J, Sonesson B, Blitz M 1985 An electromyographic analysis of the temporalis function of normal ocelusion. American Journal of Orthodontics 87: 230-239 
Bishara S E, Jakobsen J R 1985 Longitudinal changes in three normal facial types. American Journal of Orthodontios 88: 466-502

Bjōrk A, Skjeller V 1976 Postnatal growth and development of the maxillary complex. In McNamara J A Jr (ed) Factors affecting the growth of the midface. Monograph Number 6, Craniofacial growth series, Center for Human Growth and Development, University of Michigan, Ann Arbor, Michigan pp 61-99

Björk A, Skieller V 1983 Normal and abnormal growth of the mandible. A synthesis of longitudinal cephalometric implant studies over a period of 25 years. European Journal of Orthodontics 5: 1-46

Dinc S, Kober M 1985 Bisskraftmessungen an 9 bis 11jährigen Kindern. Med. Diss. University of Berne

Feller M 1986 Kephalometrische Untersuchung neunjähriger Berner Schulkinder. Med. Diss. University of Berne

Floystrand F, Kleven $E$, Oeilo $G 1982$ A novel miniature bite force recorder and its clinical application. Acta Odontologica Scandinavica 40: 209-214

Helkimo E, Ingervall B 1978 Bite force and functional state of the masticatory system in young men. Swedish Dental Journal 2: 167-175

Ingervall B 1976 Facial morphology and activity of temporal and lip muscles during swallowing and chewing. Angle Orthodontist 46: $372-380$

Ingervall B, Thilander B 1974 Relation between facial morphology and activity of the masticatory muscles. Journal of Oral Rehabilitation I: 131-147

Ingervall B, Helkimo E 1978 Masticatory muscle force and facial morphology in man. Archives of Oral Biology 23: 203-206

Ingervall B, Egermark-Eriksson I 1979 Function of temporal and masseter muscles in individuals with dual bite. Angle Orthodontist 49: 131-140
Ingervall B, Bitsanis E 1986 Function of masticatory muscles during the initial phase of activator treatment. European Journal of Orthodontics 8: 172-184

Isaacson R J, Erdman A G, Hultgren B W 1981 Facial and dental effects of mandibular rotation. In Carison D S (ed) Craniofacial Biology. Monograph Number 10, Craniofacial growth series, Center for Human Growth and Development, University of Michigan, Ann Arbor, Michigan, pp 235-269

Möllet E 1966 The chewing apparatus. Acta Physiologica 69: suppl 280

Proffit W R, Fields H W 1983 Occlusal forces in normal and long-face children. Journal of Dental Research 62: 571-574

Proffit W R, Fields H W, Nixon W L 1983 Ocelusal forces in normal and long-face adults. Journal of Dental Research 62: $566-570$

Ralston H J 1961 Uses and limitations of electromyography in the quantitative study of skeletal muscle function. American Journal of Orthodontics 47: 521-530

Ringqvist M 1973 Isometric bite force and its relation to dimensions of the facial skeleton. Acta Odontologica Scandinavica 31: 35-42

Riolo M L, Moyers R E, McNamara J A Jr, Hunter W S 1974 An atlas of craniofacial growth. Cephalometric standards from the University school growth study, University of Michigan. Monograph Number 2, Craniofacial growth series, Center for Human Growth and Development, University of Michigan, Ann Arbor, Michigan

Spyropoulos M N 1985 An early approach for the interception of skeletal open bites: A preliminary report. Journal of Pedodontics 9: 200-209

Thüer U, Janson T, Ingervall B 1985 Application in children of a new method for the measurement of forces from the lips on the teeth. European Journal of Orthodontics 7: 63-78 